\title{
Frequency Reconfigurable Circular Patch Antenna with an Arc-Shaped Slot Ground Controlled by PIN Diodes
}

\author{
Yao Chen, ${ }^{1}$ Longfang Ye, ${ }^{1}$ Jianliang Zhuo, ${ }^{1}$ Yanhui Liu, ${ }^{1}$ Liang Zhang, \\ Miao Zhang, ${ }^{1}$ and Qing Huo Liu ${ }^{2}$ \\ ${ }^{1}$ Institute of Electromagnetics and Acoustics and Department of Electronic Science, Xiamen University, Xiamen 361005, China \\ ${ }^{2}$ Department of Electrical and Computer Engineering, Duke University, Durham 27708, USA
}

Correspondence should be addressed to Longfang Ye; lfye@xmu.edu.cn

Received 24 August 2016; Revised 16 December 2016; Accepted 16 January 2017; Published 14 March 2017

Academic Editor: Mohammod Ali

Copyright (C) 2017 Yao Chen et al. This is an open access article distributed under the Creative Commons Attribution License, which permits unrestricted use, distribution, and reproduction in any medium, provided the original work is properly cited.

In this paper, a compact frequency reconfigurable circular patch antenna with an arc-shaped slot loaded in the ground layer is proposed for multiband wireless communication applications. By controlling the ON/OFF states of the five PIN diodes mounted on the arc-shaped slot, the effective length of the arc-shaped slot and the effective length of antennas current are changed, and accordingly six-frequency band reconfiguration can be achieved. The simulated and measured results show that the antenna can operate from $1.82 \mathrm{GHz}$ to $2.46 \mathrm{GHz}$, which is located in DCS1800 (1.71-1.88 GHz), UMTS (2.11-2.20 GHz), WiBro (2.3-2.4 GHz), and Bluetooth $(2.4-2.48 \mathrm{GHz})$ frequency bands and so forth. Compared to the common rectangular slot circular patch antenna, the proposed arc-shaped slot circular patch antenna not only has a better rotational symmetry with the circular patch and substrate but also has more compact size. For the given operating frequency at $1.82 \mathrm{GHz}$, over $55 \%$ area reduction is achieved in this design with respect to the common design with rectangular slot. Since the promising frequency reconfiguration, this antenna may have potential applications in modern multiband and multifunctional mobile communication systems.

\section{Introduction}

Antenna as a key and critical component plays an important role in wireless telecommunication systems. With the rapid development of the multiband and multifunction wireless communication platforms in recent years, reconfigurable antennas capable of changing its operating frequency, bandwidth, far-field radiation pattern, or polarization properties are increasingly needed to satisfy diverse communication requirements. Generally, reconfigurable antennas can be classified according to the antenna parameter that is dynamically adjusted, typically the frequency of operation, radiation pattern, or polarization. Compared to traditional antennas, frequency reconfigurable antennas offer many advantages such as compact size, similar radiation pattern, and proper gain for all desired frequency bands. Besides, reconfigurable antenna as a multifunctional antenna can reduce the number of components, sizes, and hardware complexities of the wireless system. The mechanism of the frequency reconfigurable antenna is changing the current distribution by mechanical or electrical ways. Electrically reconfigurable antennas can be realized by employing switches such as MEMS switches, PIN diodes, or varactors [1], which have been extensively studied for their promising potential applications in many fields. For example, frequency reconfigurable antennas are designed using RF MEMS switches in $[2,3]$. In these works, the operating frequency band is changed by activating or deactivating the RF MEMS actuators. In [4], a varactor-tuned frequency reconfigurable antenna based on a dual frequency microstrip antenna is presented, and a high tuning frequency range is achieved from $1.037 \mathrm{GHz}$ to $1.485 \mathrm{GHz}$ when the bias voltage is varied from 0 to $-30 \mathrm{~V}$. And in [5], a continuously tunable frequency reconfigurable antenna based on a circular monopolar patch antenna using varactor is presented. Because of the advantages of low biasing voltage, high tuning speed (1-100 ns), high power 


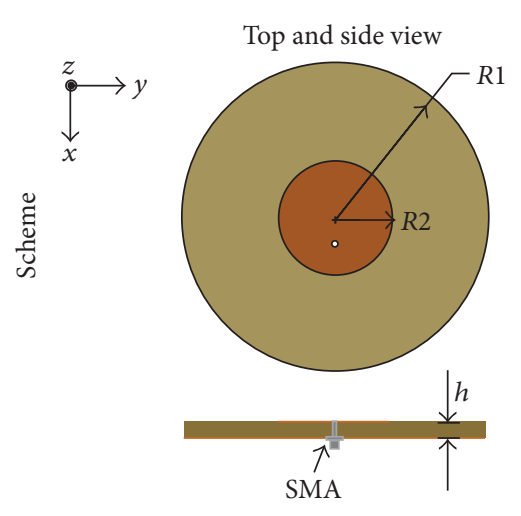

(a)

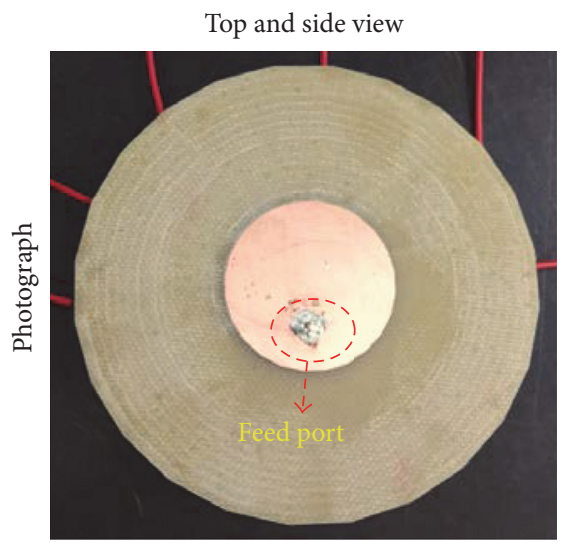

(c)

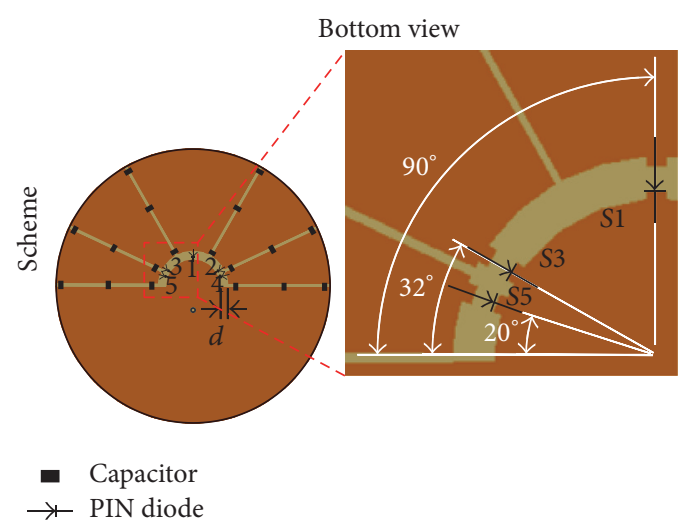

(b)

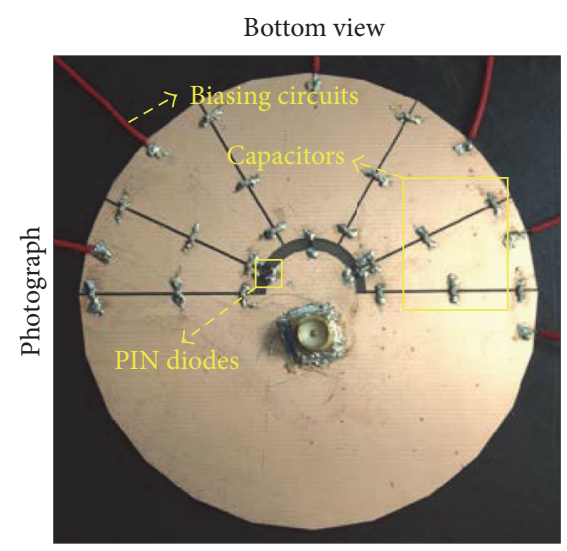

(d)

FIGURE 1: Scheme and photograph of the proposed reconfigurable antenna.

handling capability, high reliability, and extremely low cost, PIN diodes based frequency reconfigurable antenna has attracted tremendous research interest [6-12]. Recently, lots of frequency reconfigurable antennas based on UWB antenna [3], circular monopolar patch antenna [5], slot antennas [7-11], bow-tie antenna [12], and PIFA [13] were proposed for multiband wireless communication applications like low frequency LTE band (699-862 MHz), high frequency LTE band (2496-2690 MHz), Bluetooth (2400-2480 MHz), WLAN (5.15-5.825 GHz), WiMAX (2500-2690 MHz), and so forth. Moreover, some frequency reconfigurable antennas are designed for LTE or WWAN mobile handset applications $[14,15]$.

In this paper, a compact frequency reconfigurable backfed circular patch antenna is proposed, designed, simulated, and tested. This work is inspired by the antenna design in our previous work [16] but goes further by demonstrating a new and compact geometry with circular ground plane, more switching bands, and better reconfigurable properties. RF PIN diodes are employed and mounted on the arc-shaped slot of the antenna's ground plane to achieve six different frequency bands with good frequency reconfiguration performance switching from $1.8 \mathrm{GHz}$ to $2.46 \mathrm{GHz}$, which is located in DCS1800 (1.71-1.88 GHz), UMTS (2.11-2.20 GHz),
WiBro (2.3-2.4 GHz), and Bluetooth (2.4-2.48 GHz) frequency bands and so forth. Compared to the common rectangular slot circular patch antenna, the proposed arcshaped slot circular patch antenna not only has a better rotational symmetry with the circular patch and substrate but also has more compact sizes and simplifier structure. For the given operating frequency, over $55 \%$ area reduction is achieved in this design with respect to the common one.

\section{Design and Configuration}

The configuration scheme and the photograph of the proposed antenna are shown in Figure 1. The antenna is fabricated on the FR4 substrate with the permittivity of 4.4 and the thickness $(h)$ of $1.4 \mathrm{~mm}$ by using mechanical process (LPKF ProtoMat S103 circuit board plotter). The radius of the antenna $R 1$ is $40 \mathrm{~mm}$. The top view of the antenna is a circular patch with radius $R 2$ of $15 \mathrm{~mm}$ fed by a coaxial probe. The back feeding port is located in the symmetry axis and $7 \mathrm{~mm}$ away from the center of the circular patch. Based on the circular shape of the substrate and the radiation patch, the slot in the ground is designed into an arc-shaped slot to reduce the size and realize better rotational symmetry of the ground plane. The total length of the arc-shaped slot is about $30 \mathrm{~mm}$, 


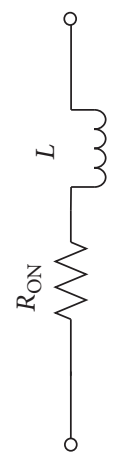

(a)

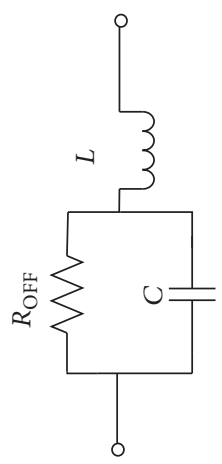

(b)
Figure 2: Equivalent circuit models of PIN diodes under (a) ON state with $1 \mathrm{~V}$ forward biasing and (b) OFF state with $0 \mathrm{~V}$ reverse biasing.

and the width of the slot is $2 \mathrm{~mm}$. Five PIN diodes as switches are symmetrically located in the slot by $20^{\circ}, 32^{\circ}, 90^{\circ}, 148^{\circ}$, and $160^{\circ}$, respectively. Meanwhile, as shown in the bottom view of the proposed antenna, the ground plane is divided into six isolated parts by small slots with a width of $0.3 \mathrm{~mm}$ to provide independent DC biasing for PIN diodes. And three capacitors with the capacitance of $47 \mathrm{pF}$ are mounted on each slot to provide RF and microwave continuity for the whole antenna ground plane. BAR-64-02 PIN diodes are mounted on the arc-shaped slot in ground plane to achieve frequency reconfiguration [17].

\section{Equivalent Circuit Models of PIN Diodes}

PIN diodes are the most commonly used switching components for RF and microwave applications. And in this work, PIN diodes are also chosen as the switching components to achieve the frequency reconfiguration in the antenna design. In order to accurately simulate and predict the antennas properties, the simplified PIN diodes equivalent circuit models are obtained from the datasheet of BAR-6402. The equivalent circuit models of PIN diodes for ON/OFF states are shown in Figure 2, which consists of a series parasitic inductance $(L)$ and an intrinsic resistance $\left(R_{\mathrm{ON}}\right)$ when the PIN diode is ON, while a series $L$ and an intrinsic capacitance $(C)$ in parallel with a resistance $\left(R_{\mathrm{OFF}}\right)$ when the PIN is OFF. Under ON state ( $1 \mathrm{~V}$ forward biasing), the values of inductance $(L)$ and intrinsic resistance $\left(R_{\mathrm{ON}}\right)$ are $0.45 \mathrm{nH}$ and $1.5 \Omega$, respectively. And under OFF state $(0 \mathrm{~V}$ reverse biasing), the value of capacitance $(C)$ and resistance $\left(R_{\mathrm{OFF}}\right)$ are $0.25 \mathrm{pF}$ and $2.5 \mathrm{k} \Omega$, respectively. Based on these equivalent circuit models, commercial software ANSYS High Frequency Structure Simulator (HFSS) based on finite element method is applied to further design, simulate, and optimize the antenna's dimensions and performance.

\section{Results and Discussion}

The proposed frequency reconfigurable antenna is based on back-fed circular patch antenna with an arc-shaped slot (length of $30 \mathrm{~mm}$ and width of $2 \mathrm{~mm}$ ) in the ground plane. The top circular patch and the arc-shaped slot on the ground plane of this arc-shaped slot patch antenna are excited by the coaxial back feed to achieve antenna radiation. As shown in Figure 3, the radii $R 1$ and $R 2$ of this arc-shaped slot circular patch antenna are $40 \mathrm{~mm}$ for the operating frequency of 1.9 GHz without any lumped elements or biasing network. While, if a common rectangular slot with the same length of $30 \mathrm{~mm}$ and width of $2 \mathrm{~mm}$ in the ground plane is employed, longer radius $R 1$ of $60 \mathrm{~mm}$ is needed for the antenna to achieve the same operating frequency at $1.9 \mathrm{GHz}$. The radius $R 2$ is fixed as $15 \mathrm{~mm}$ in both cases. In other words, the proposed antenna has the advantage of compact size and about $55.6 \%$ area reduction is achieved compared to the common rectangular slot antenna. Moreover, the operating frequency of this arc-shaped slot circular patch antenna can be directly adjusted by tuning the radius $R 2$. As shown in Figure 4, the resonant frequency decreases from $2.19 \mathrm{GHz}$ to $1.72 \mathrm{GHz}$ as $R 2$ increases from $13 \mathrm{~mm}$ to $17 \mathrm{~mm}$ while keeping other dimension fixed. This implies that, for a given operating frequency, further antenna size reduction can be easily realized by reducing $R 1$ while properly increasing $R 2$. Besides, using higher permittivity material substrate will also contribute to the antenna miniaturization.

The proposed frequency reconfigurable antenna is realized by integrating PIN diodes to the arc-shaped slot circular patch antenna and introducing proper biasing for each diode using external DC supply. Table 1 shows the configuration of the PIN switches and the simulated and measured antenna properties of each switching band, where 1 represents $\mathrm{ON}$ state and 0 represents OFF state in the table. Clearly, by electrically controlling the ON/OFF states of the five PIN diodes, six reconfigurable frequency bands can be obtained. The basic mechanism for this frequency reconfiguration is that the effective length of the arc-shaped slot and the effective length of antennas current are changed, accordingly resulting in the resonant frequency tuning from F1 to F6. To visually observe this phenomenon, the normalized magnitude and vector current distributions on the ground plane of the antenna at F1, F3, and F5 states are demonstrated in Figure 5. It is found that the operating frequency changes with the current distribution changes as expected. When the antenna works at a lower resonant frequency, the effective length of the arc-shaped slot and the effective length of antennas current distribution are larger because all PIN diodes are at OFF state. Besides, the simulated radiation efficiency and the measured peak gain of the proposed antenna for each switching state are also presented in Table 1. It is found that the general trends for efficiency and gain are similar to each other. As expected from the efficiency, the antenna gain at the switching frequency F1 has the highest value. This is because almost no RF signal goes through all PIN diodes with OFF state when the antenna operated at F1 state. Thus negligible ohmic losses caused by PIN diodes are introduced. While at F3 and F5 states, RF signal will pass through the ON state PIN diodes, which results in larger ohmic losses and therefore lower the antenna radiation efficiency and the realized peak gain. 

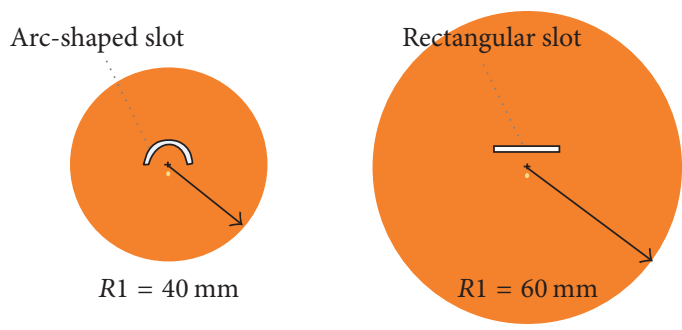

(a) Bottom view of patch antennas with different slots

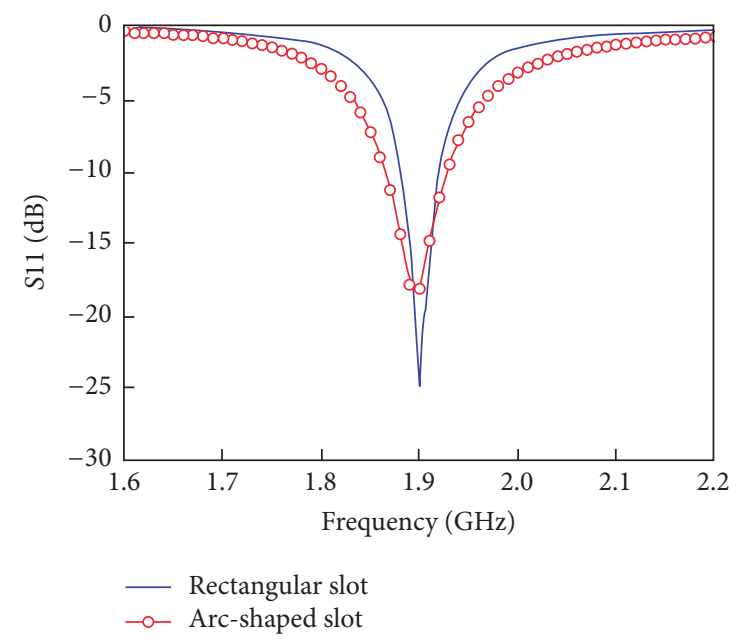

(b) Simulated $S 11$ results for antennas with different slots

FIGURE 3: Comparison between rectangular slot antenna and the proposed arc-shaped slot antenna.

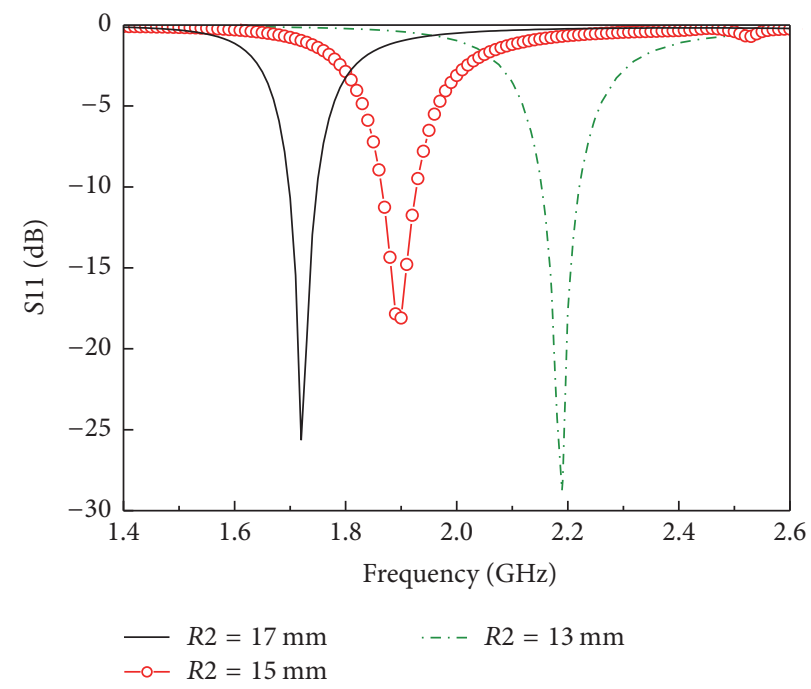

FIGURE 4: Resonant frequency tuning of the proposed arc-shaped slot antenna by radius $R 2$.

As shown in Figure 6, both the simulated and the measured results show good frequency reconfiguration performance with $S 11$ less than $-10 \mathrm{~dB}$ at all operating bands with respect to the switching frequencies in Table 1 . We observe that the simulated $-10 \mathrm{~dB}$ bandwidth results are ranging from $50 \mathrm{MHz} \sim 80 \mathrm{MHz}$ with corresponding percentage bandwidth of $2.7 \% \sim 3.25 \%$ for F1 F6 states, while the measured $-10 \mathrm{~dB}$ bandwidth results are ranging from $60 \mathrm{MHz} 90 \mathrm{MHz}$ with corresponding percentage bandwidth of $2.7 \%$ 3.5\% for F1 F6 states, which are close to each other for both cases. It is found that switching frequencies $\mathrm{F} 1(1.82 \mathrm{GHz}), \mathrm{F} 2$ $(2.18 \mathrm{GHz}), \mathrm{F} 4(2.38 \mathrm{GHz})$, and $\mathrm{F} 5(2.44 \mathrm{GHz})$ are located in DCS1800 (1.71-1.88 GHz), UMTS (2.11-2.20 GHz), WiBro $(2.3-2.4 \mathrm{GHz})$, and Bluetooth $(2.4-2.48 \mathrm{GHz})$ frequency bands, respectively; and F3 $(2.22 \mathrm{GHz})$ is located in the frequency band of $2.2-2.29 \mathrm{GHz}$ used for space research and Earth exploration-satellite communications. Because this proposed structure has considerable design freedom, different given operating frequency bands can be easily achieved during the design process according to the length of the arcshaped slot and the number of the switching components. Generally, the experimental results indicate good agreement with the simulation results with little resonant frequency offset (see Figure 6). This small difference mainly results from the accuracy of the PIN diodes equivalent model, parasitic parameters, and manufacturing tolerances.

Furthermore, the simulated and measured radiation patterns of the proposed antenna in $x-z$ plane and $y-z$ plane at the six different resonating frequencies are shown in Figure 7. It is found that the corresponding radiation patterns are similar to each other with bidirectional $x-z$ plane and omnidirectional $y-z$ plane. However, due to the manufacturing tolerance and the additional parasitic parameters caused by introducing five PIN diodes, eighteen 
TABLE 1: Switch configuration and corresponding antenna properties.

\begin{tabular}{|c|c|c|c|c|c|c|c|c|c|c|c|}
\hline States & S4 & $S 2$ & $S 1$ & S3 & S5 & $\begin{array}{c}\text { Simulated } f \\
(\mathrm{GHz})\end{array}$ & $\begin{array}{c}\text { Measured } f \\
\quad(\mathrm{GHz})\end{array}$ & $\begin{array}{c}\text { Simulated } \\
-10 \mathrm{~dB} \\
\text { bandwidth } \\
(\mathrm{MHz})\end{array}$ & $\begin{array}{c}\text { Measured } \\
-10 \mathrm{~dB} \\
\text { bandwidth } \\
(\mathrm{MHz})\end{array}$ & $\begin{array}{l}\text { Simulated } \\
\text { radiation } \\
\text { efficiency }\end{array}$ & $\begin{array}{c}\text { Measured } \\
\text { peak gain } \\
\quad(\mathrm{dB})\end{array}$ \\
\hline $\mathrm{F} 1$ & 0 & 0 & 0 & 0 & 0 & 1.82 & 1.84 & 50 & 60 & $72 \%$ & 7.10 \\
\hline F2 & 1 & 1 & 0 & 1 & 1 & 2.18 & 2.18 & 60 & 74 & $55 \%$ & 4.13 \\
\hline F3 & 0 & 1 & 0 & 1 & 0 & 2.23 & 2.22 & 65 & 70 & $57 \%$ & 4.60 \\
\hline F4 & 0 & 0 & 1 & 0 & 0 & 2.35 & 2.38 & 80 & 96 & $72 \%$ & 4.36 \\
\hline F5 & 0 & 1 & 1 & 1 & 0 & 2.41 & 2.44 & 80 & 80 & $67 \%$ & 4.72 \\
\hline F6 & 1 & 1 & 1 & 1 & 1 & 2.46 & 2.46 & 80 & 90 & $56 \%$ & 4.69 \\
\hline
\end{tabular}

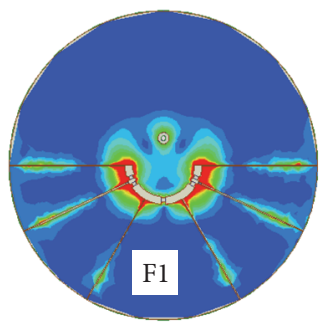

(a)

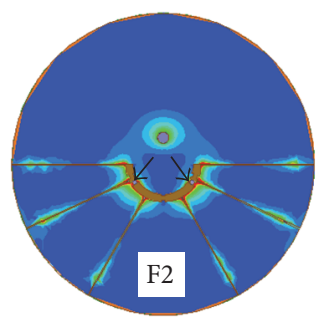

(b)

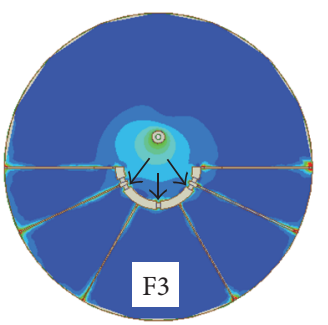

(c)

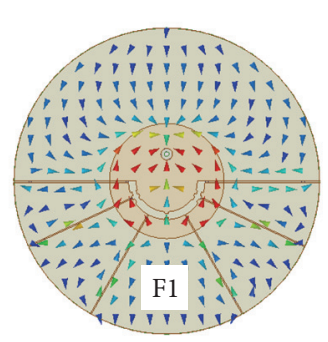

(d)

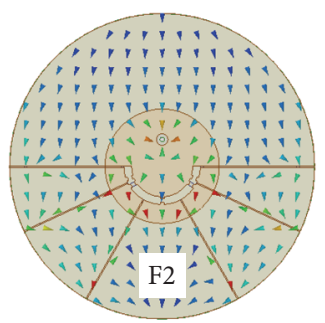

(e)

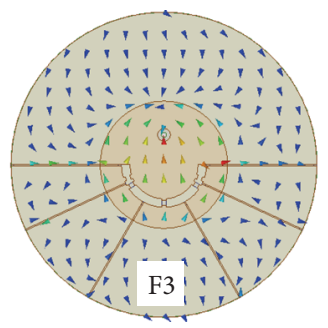

(f)
FIGURE 5: The normalized magnitude (left) and vector (right) current distributions on the ground plane at different switching states, where (a) and (d) are at F1 state, (b) and (e) are at F3 state, (c) and (f) are at F5 state, and the black arrows point to the PIN diodes with $\mathrm{ON}$ state.

capacitors, and several bias wires in the ground plane, the measured radiation patterns are worse than the simulated ones. Besides, linear polarization results at all switching states are also observed. Generally, these six radiation patterns at different switching frequencies exhibited certain similarity to each other, which schematically verified the design of
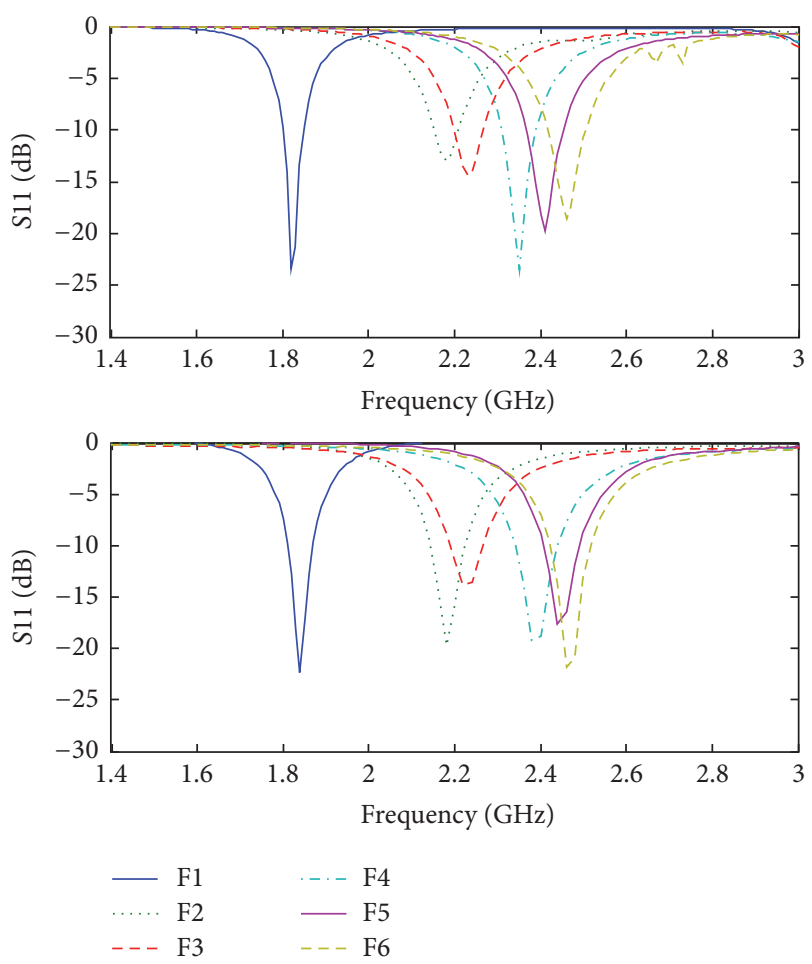

FIGURE 6: The simulated and measured $S 11$ of the proposed antenna.

proposed frequency reconfigurable antenna. As to excellent performance, convenient adjusting, and simple structure, this reconfigurable antenna may have many potential applications in modern multiband and multifunctional mobile communication systems.

\section{Conclusion}

A compact frequency reconfigurable circular antenna is proposed, simulated, and measured. It has been demonstrated that the frequency reconfiguration can be achieved by changing the length of the arc-shaped slot using the RF equivalent circuit model of PIN diodes. Good frequency reconfiguration performance with $S 11$ less than $-10 \mathrm{~dB}$ at all operating frequency bands is obtained. The corresponding radiation patterns are similar to each other with bidirectional $x-z$ 

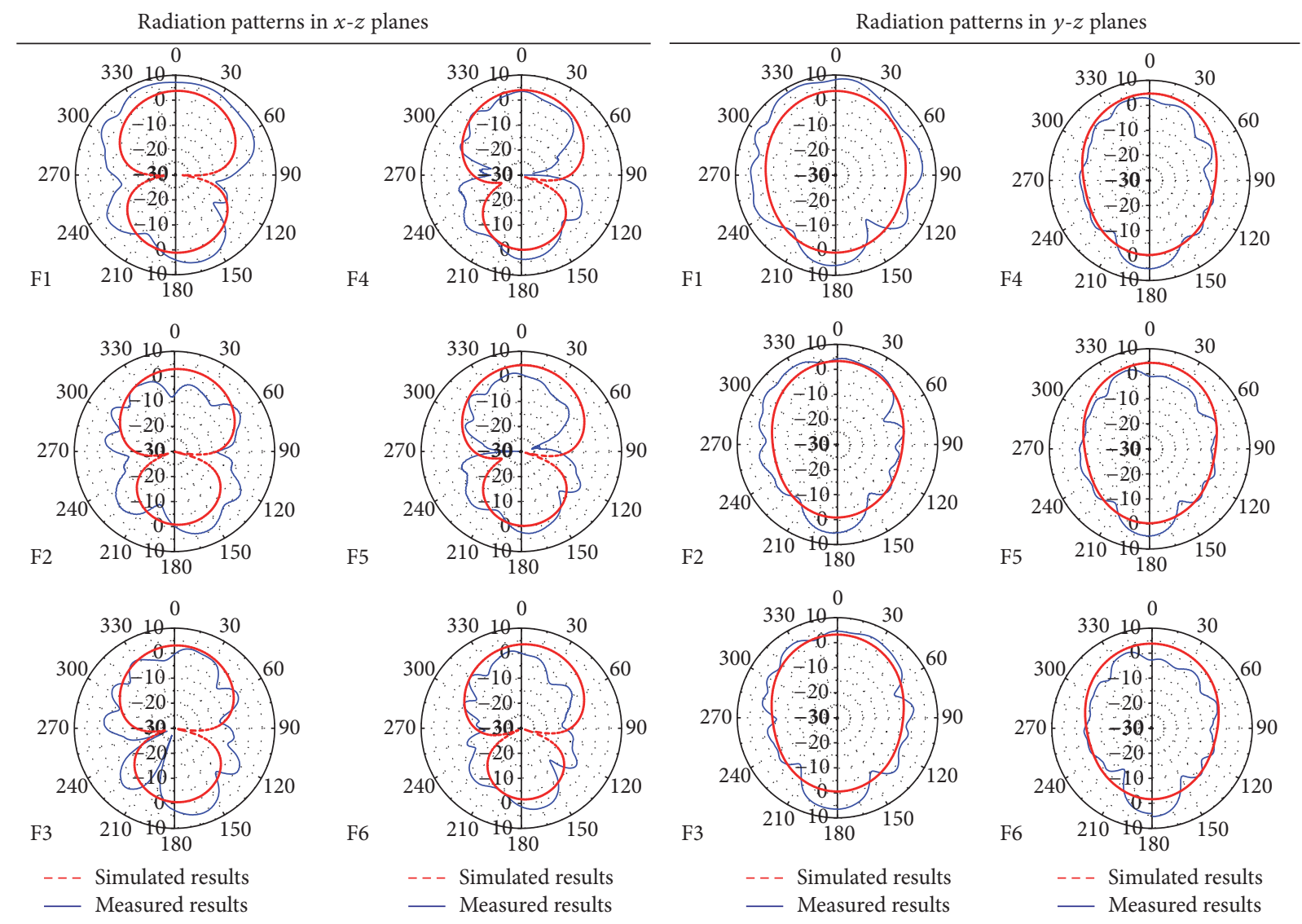

FIGURE 7: Simulated and measured radiation patterns in $x-z$ planes and $y-z$ planes, respectively, at different states.

plane and omnidirectional $y-z$ plane under different biasing states. As to excellent performance, convenient adjusting, and simple structure, the proposed reconfigurable antenna may have many potential applications in modern multiband and multifunctional mobile communication systems.

\section{Conflicts of Interest}

The authors declare that they have no conflicts of interest.

\section{Acknowledgments}

The authors thank Dr. Xiaofan Yang, Dr. Manxi Wang, and Min Yu for their fruitful discussion and technical support. This work was supported in part by the National Natural Science Foundation of China (61601393), the Natural Science Foundation of Fujian Province of China (2016J01321), the State Key Laboratory of Complex Electromagnetic Environment Effects on Electronics and Information System Foundation (CEMEE2015K0202B), and the Fundamental Research Funds for the Central Universities of China (20720150083).

\section{References}

[1] N. Haider, D. Caratelli, and A. G. Yarovoy, "Recent developments in reconfigurable and multiband antenna technology," International Journal of Antennas and Propagation, vol. 2013, Article ID 869170, 14 pages, 2013.
[2] B. A. Cetiner, G. R. Crusats, L. Jofre, and N. Biyikli, "RF MEMS integrated frequency reconfigurable annular slot antenna," IEEE Transactions on Antennas and Propagation, vol. 58, no. 3, pp. 626-632, 2010.

[3] Y. Li, W. Li, and Q. Ye, "Compact reconfigurable UWB antenna integrated with SIRs and switches for multimode wireless communications," IEICE Electronics Express, vol. 9, no. 7, pp. 629-635, 2012.

[4] S. V. Shynu, G. Augustin, C. K. Aanandan, P. Mohanan, and K. Vasudevan, "Design of compact reconfigurable dual frequency microstrip antennas using varactor diodes," Progress in Electromagnetics Research, vol. 60, pp. 197-205, 2006.

[5] L. Ge and K.-M. Luk, "Frequency-reconfigurable low-profile circular monopolar patch antenna," IEEE Transactions on Antennas and Propagation, vol. 62, no. 7, pp. 3443-3449, 2014.

[6] T.-Y. Han and C.-T. Huang, "Reconfigurable monopolar patch antenna," Electronics Letters, vol. 46, no. 3, pp. 199-200, 2010.

[7] D. Peroulis, K. Sarabandi, and L. P. B. Katehi, "Design of reconfigurable slot antennas," IEEE Transactions on Antennas and Propagation, vol. 53, no. 2, pp. 645-654, 2005.

[8] H. A. Majid, M. K. Abdul Rahim, M. R. Hamid, N. A. Murad, and M. F. Ismail, "Frequency-reconfigurable microstrip patchslot antenna," IEEE Antennas and Wireless Propagation Letters, vol. 12, pp. 218-220, 2013.

[9] H. A. Majid, M. K. A. Rahim, M. R. Hamid, and M. F. Ismail, "A compact frequency-Reconfigurable narrowband microstrip slot antenna," IEEE Antennas and Wireless Propagation Letters, vol. 11, pp. 616-619, 2012. 
[10] H.-Y. Li, S.-C. Chen, H.-P. Chen, W.-C. Ran, and J.-S. Fua, "A frequency-reconfigurable slot loop antenna using ferroelectric MIM capacitors," IEICE Electronics Express, vol. 10, no. 16, Article ID 20130521, 2013.

[11] H. A. Majid, A. Rahim, M. R. Hamid, N. A. Murad, and M. F. Ismail, "Frequency reconfigurable microstrip patch-slot antenna with directional radiation pattern," Progress in Electromagnetics Research, vol. 144, pp. 319-328, 2014.

[12] T. Li, H. Zhai, X. Wang, L. Li, and C. Liang, "Frequencyreconfigurable bow-tie antenna for bluetooth, WiMAX, and WLAN applications," IEEE Antennas and Wireless Propagation Letters, vol. 14, pp. 171-174, 2015.

[13] J.-H. Lim, G.-T. Back, Y.-I. Ko, C.-W. Song, and T.-Y. Yun, "A reconfigurable PIFA using a switchable PIN-diode and a fine-tuning varactor for USPCS/WCDMA/m-WiMAX/WLAN," IEEE Transactions on Antennas and Propagation, vol. 58, no. 7, pp. 2404-2411, 2010.

[14] S. W. Lee and Y. Sung, "Compact frequency reconfigurable antenna for LTE/WWAN mobile handset applications," IEEE Transactions on Antennas and Propagation, vol. 63, no. 10, pp. 4572-4577, 2015.

[15] J. Ilvonen, R. Valkonen, J. Holopainen, and V. Viikari, "Multiband frequency reconfigurable $4 \mathrm{G}$ handset antenna with MIMO capability," Progress in Electromagnetics Research, vol. 148, pp. 233-243, 2014.

[16] X. F. Yang, Y. Chen, L. F. Ye, M. X. Wang, M. Yu, and Q. H. Liu, "Frequency reconfigurable circular patch antenna using PIN diodes," in Proceedings of the IEEE International Conference on Microwave and Millimeter Wave Technology (ICMMT '16), Beijing, China, June 2016.

[17] Datasheet of BAR64-02 Silicon PIN diode, http://www.infineon-BAR64series-DS-v01_02-EN.pdf?fileId=5546d4625607bd$130156121 f 289 \mathrm{c} 38 \mathrm{~b} 5$. 


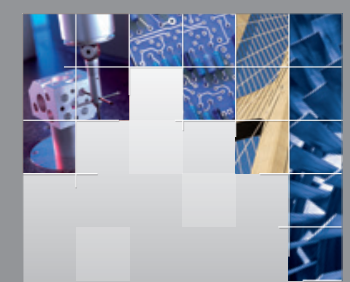

\section{Enfincering}
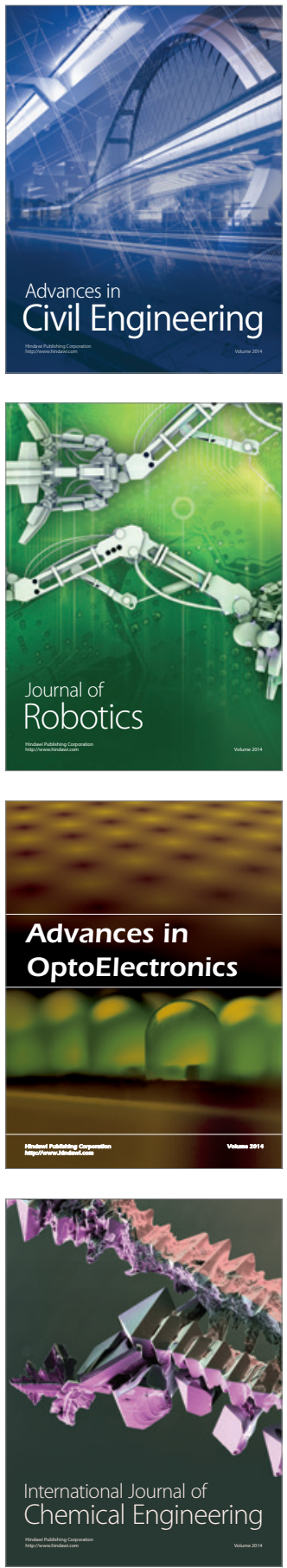

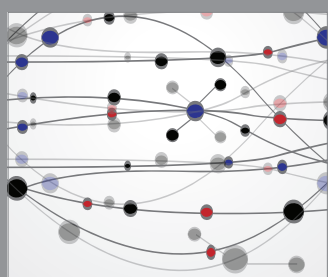

The Scientific World Journal

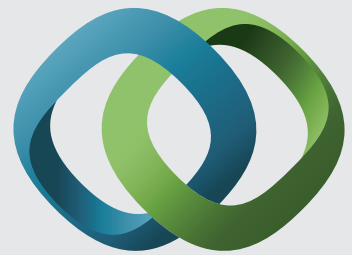

\section{Hindawi}

Submit your manuscripts at

https://www.hindawi.com
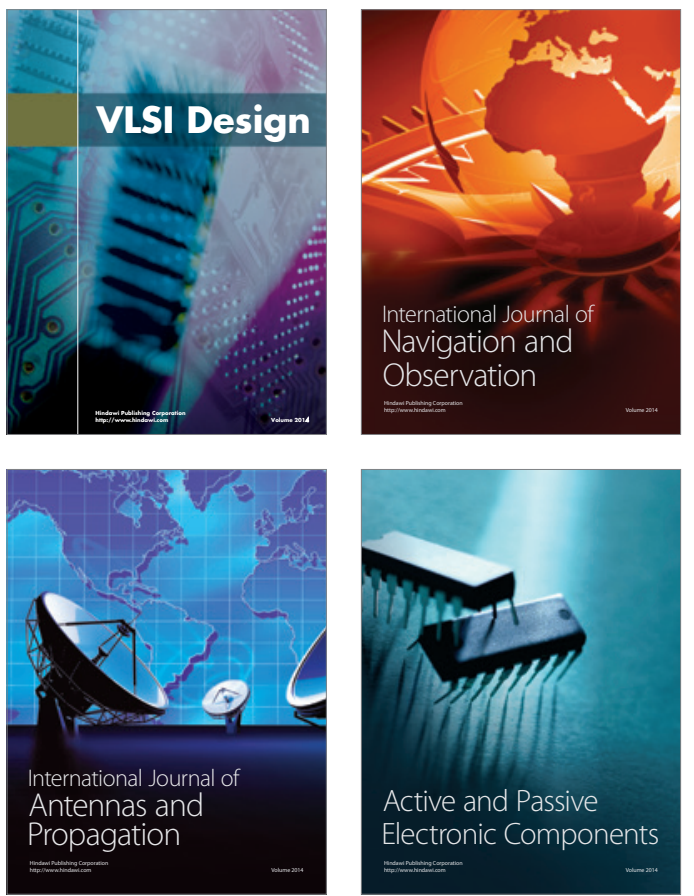
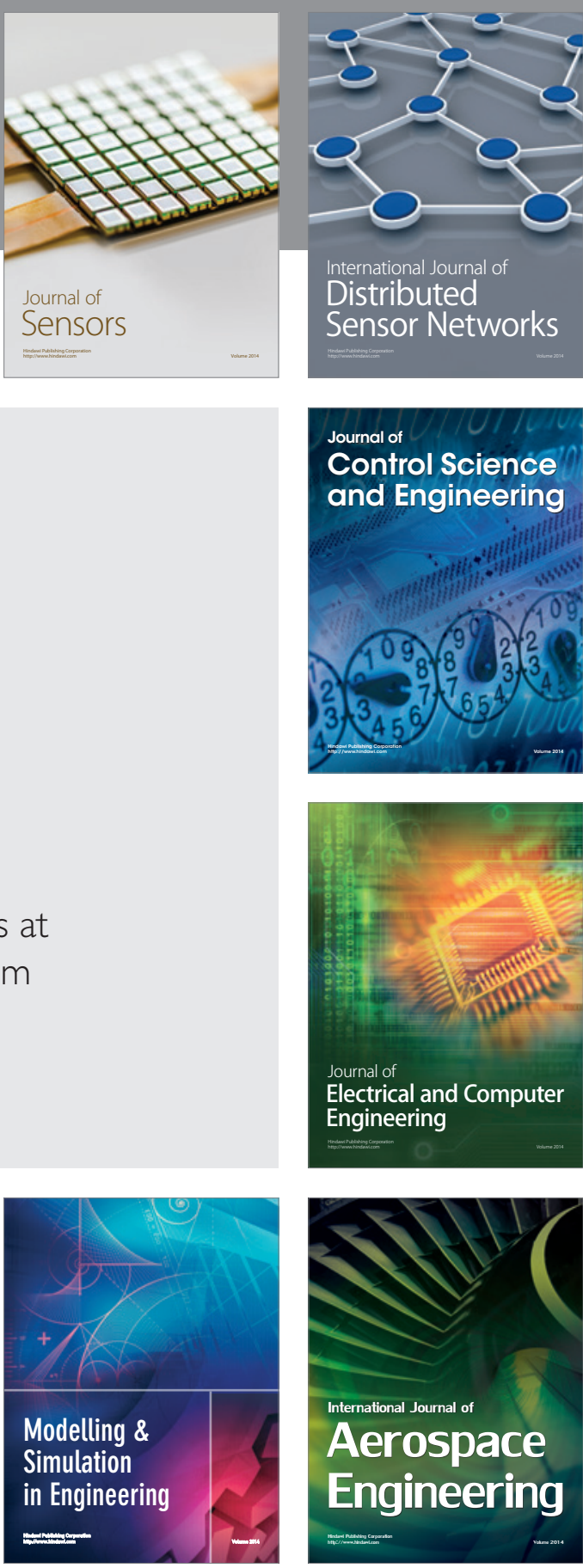

International Journal of

Distributed

Sensor Networks

$-$

Joumal of

Control Science

and Engineering
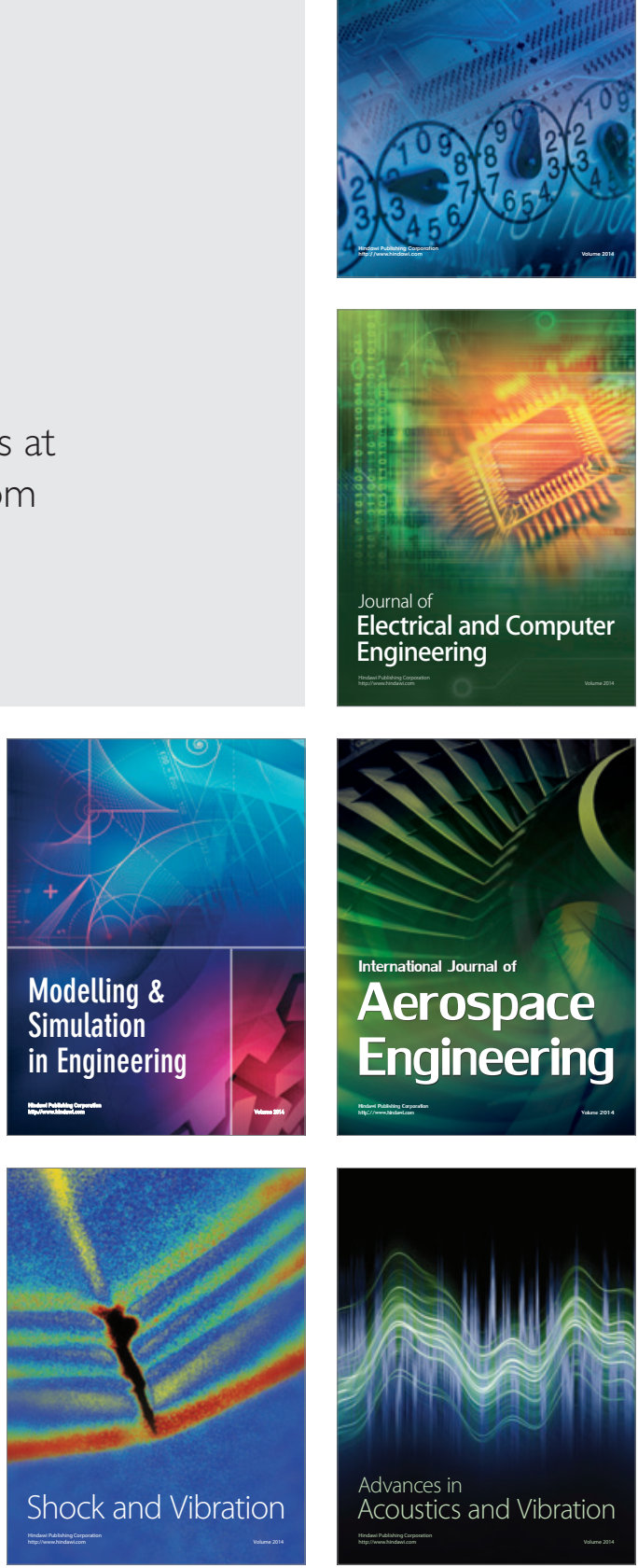